\title{
Linking Attachment Avoidance and Attachment Anxiety with Eating Disorder Attitudes and Behaviours in a Sample of Nonclinical Albanian Female College Students
}

\author{
Ermira Hoxha \\ PhD Student, Department of Psychology, University of Tirana \\ Email: hoxhaermira@gmail.com
}

\author{
Doi:10.5901/mjss.2016.v7n4p
}

\section{Abstract}

The present study investigated the link between attachment avoidance and attachment anxiety with mother and eating disorderd attitudes and behaviors in a non clinical sample of Albanian late adolescent female students using the quantitative scientific research method. The sample consisted of 779 female college students, enrolled at two public Albanian universities ( University of Tirana and University of Shkoder) ranging from 18 to 21 years of age (mean age 19.25,SD=.885). Participants completed the following self-reported instruments: the Experience in Close Relationship-Relationship Structures questionnaire (Fraley,Brennan\& Waller,2000) and subscales of Body Dissatisfaction, Drive for Thinness and Bulimia of Eating Disorder Inventory- 3 (Garner, 2004). Results revealed that in relation to attachment avoidance and attachment anxiety with mother, female students displayed higher levels of body dissatisfaction, drive for thinness and bulimia when compared to female students scoring low in attachment avoidance and anxiety with their mother. The strongest associations were found between attachment avoidance and body dissatisfaction and between attachment anxiety and bulimia. Prevention and treatment programs focused on attachment relationships are recommended.

Keywords: attachment avoidance, attachment anxiety, BMI, body dissatisfaction, drive for thinness, bulimia.

\section{Introduction}

Eating disorders represent complex pathologies because of the implication of multidimensional risk and maintenance factors. At their core, eating disorders are characterized by severe disturbances in eating behaviours such as extreme reduction of food intake, binge eating and/or feelings of extreme distress and concern about body weight or shape. Typically, eating disorders appear during mid adolescence or young adulthood and mostly on girls and young women. Research on aetiology of eating disorders highlights a variety of risk factors (biological, individual, familiar and sociocultural) even though the precise mechanisms of interaction between these underlying factors remain elusive. The two most commonly known categories of eating disorders are anorexia and bulimia nervosa, which are characterized by unrealistic fear of weight gain, self starvation and extreme distortion of body image. People with anorexia in some cases engage in purging behaviours through the use of laxatives, diuretics or vomiting to avoid gaining weight. In many cases anorexics are underweight which make their fears even more unrealistic. At the other part, people with bulimia have a normal or near normal body weight, but they also have a distorted body image and fear of gaining weight. As a consequence bulimics tend to engage in dieting and in episode of binge eating which are followed by negative affects like shame, ineffectiveness, feeling out of control etc. To reduce these feelings and to avoid gaining weight people with bulimia usually practice self-induced vomiting, laxatives, fasting or excessive dieting.

The distorted body image plays a crucial role in dysfunctional eating attitudes and behaviours. Body dissatisfaction as a result of misperceived weight status is found to be greater through late adolescence than early adolescence (Clay,Vignoles \& Ditmar, 2005; Furnham, Badmin, Sneade, 2002; Neumark-Sztainer et al., 2002). Body dissatisfaction is defined as having negative feelings about the body (Polivy \& Herman,2002) and has crucial role in the development of eating disorder symptomatology although not all those who are dissatisfied with their body develop an eating disorder.

Attachment theory highlights the crucial role of early attachment relationships of infant with his mother in his overall wellbeing. Attachment refers to one specific aspect of the relationship between a child and a parent with the purpose to make a child feel safe and secure. When the attachment figure is unresponsive, unreliable or unpredictable, the sense of security in child is threatened and different patterns of attachment insecurity are likely to develop. Adult attachment theories suggest that individual differences in attachment identified in childhood appear to be relatively stable over time (Fraley, 2002). The original attachment patterns identified and measured by Ainsowrth et al., (1978) among children (secure, anxious-avoidant and anxious-ambivalent attachment) were further developed so to be applicable for adults. 
Hazan and Shaver (1987) developed a self reported measure of adult attachment styles based on attachment avoidance and attachment anxiety dimensions. Specifically, anxiety attachment refers to the degree of preoccupation that the attachment figure will not be responsive and disponible, while avoidance attachment refers to the degree of distrust toward an attachment figure and the degree of attempts that the individual makes to maintain the emotional distance from attachment figure because of fear of rejection (Brennan, Clark\& Shaver, 1998) Dimensional scales of adult attachment styles were further extended by a number of investigators (e.g., Bartholomew \& Horowitz, 1991; Collins \& Read,1990; Fraley, Brennan \& Waller, 2000).

Research indicates that attachment insecurity is related to anxiety (Warren, Huston, Egeland, \& Sroufe, 1997), low self-esteem (Collins \& Read, 1990; Griffin \& Bartholomew, 1994; Gamble \& Roberts, 2005; Gotlib \& Kassel, 1996) and negative emotional traits (Magai, Distel,\& Liker, 1995) which are also characteristic of eating disorders. Also links has been found between attachment insecurity and eating disorders (Cole-Detke \& Kobak, 1996). A number of studies have reported that the most prevalent style of ED women is avoidant style whereas secure attachment style is negatively correlated with eating disorder symptomatology (Latzer et al., 2002; Cole-Detke \& Kobak, 1996). Some research report higher prevalence of eating disorders among individuals with higher levels of attachment avoidance (Ramacciotti et al., 2001; Latzer et al., 2002), while other investigators have found that preoccupied attachment style, characterized by high levels of attachment anxiety, is a significant predictor of high levels of body dissatisfaction, which in turn is a risk factor for eating disorders (Troisi, Di Lorenzo, Alcini, Nanni, Di Pasquale, Siracusano, 2006). Although the precise mechanisms of interplay between attachment insecurity and eating disorder are not clear, it has been suggested that symptoms of eating disorders in insecurely attached individuals may also operate as ways of emotional regulation in times of distress (Tasca et al., 2009;) or as attempts to avoid psychological distress through focusing attention on food and body weight (Polivy \& Herman, 2002). Exerting control over body weight can increase the sense of self control, including the sense of having negative emotional states under control (Fairburn, Shafran, \& Cooper, 1998).

This study aims to identify the relationship between maternal attachment avoidance and attachment anxiety of Albanian female college students and unhealthy eating attitudes and behaviours as measured through body dissatisfaction, drive for thinness and bulimia. The main research question is: Does higher levels of attachment avoidance and attachment anxiety of female college students with their mother predict higher scores on body dissatisfaction, drive for thinness and bulimia?

The objectives of the study are:

1. To describe the relationship between body mass index and body dissatisfaction, drive for thinness and bulimia in Albanian female college students.

2. To analyse the differences on body dissatisfaction, drive for thinness and bulimia levels in Albanian female college students as linked to attachment avoidance and attachment anxiety with their mothers.

\section{Methodology}

The present study has as a main research focus the examination of the link between two independent variables such as maternal attachment avoidance and attachment anxiety in Albanian female college students and body dissatisfaction, drive for thinness and bulimia as dependent variables. Data collection consisted in administration of two self - reported questionnaires used in previous similar research studies: The Experience in Close Relationship Questionnarie Relationship Structures addressing the measurement of anxiety and avoidance attachment dimension with mother, developed by Fraley, Waller and Brennan (2000) and the Eating Disorder Inventory-3, the latest version of Eating Disorder Inventory revised by Garner (2004), addressing the measurement of eating disordered behaviors and attitudes in clinical and non clinical populations.

\subsection{Participants and procedure}

The sample of study consisted of 779 nonclinical Albanian female students enrolled at two major public universities from different study programs. The participant's average age ranged from 18 years old minimum age to 21 years old the maximum age with a mean age $M=19.25$, (SD= 885$)$. Participants completed measures of drive for thinness, body dissatisfaction, bulimia and attachment with their mother. All participants provided written informed consent, after being informed on issues of confidentiality and research ethics. 


\subsection{Measures}

- Eating Disorder Inventory-3. EDI-3 was developed by Garner (2004) and is made of 12 subscales, 3 subscales assessing eating disorder attitudes and behaviours and 9 subscales assesing psychological traits associated with eating disorder symptoms. Research has validated use of the EDI with both clinical and non-clinical populations. For the purpose of this study, 3 subscales of EDI-3 (Garner, 204) were used: Body dissatisfaction, Drive for Thinness and Bulimia as a measure of eating disorder attitudes and behaviours. All subscales are based on items that can be rated on a six point scale ranging from 'always' (1) to 'never' (6). Body dissatisfaction subscale consists of 10 items and measures the belief that specific parts of the body associated with shape change or increase are too large. Drive for thinness consists in 7 items assessing the degree of concern with dieting and preoccupation with weight. Bulimia consists in 8 items reflecting the tendency of individual toward episodes of binge eating that may be followed by compensatory behaviors like self-induced vomiting. In the present study the obtained reliability (a) coefficients were .75 for body dissatisfaction, .80 for drive for thinness and. 70 for bulimia.

- The Experience in Close Relationship-Relationship Structures. The Experience in Close Relationship Relationship Structures (ECR-RS, Fraley, Brennan, \& Waller, 2000) is a self report instrument, containing 9 items that assess attachment in four areas of relationships: relationships with mother, father, romantic partners and friends. Items can be rated on a seven point Likert scale with scores ranging from 'strongly disagree' (1) to 'strongly agree' (7). In the present study only the part of questionnaire measuring the relationship with mother was used. The subscales of the ECR-RS are just as reliable as those based on longer inventories (e.g. ECR$\mathrm{R}$ ) used in similar previous research. In the present study the obtained reliability coefficients a were .78 for attachment avoidance and .80 for attachment anxiety.

\subsection{Statistical analysis}

Statistical analysis were performed using SPSS software version 20.0 for Windows. To asses differences between groups of participants identified as low versus high in attachment avoidance and low versus high in attachment anxiety dimensions a series of Mann- Whitney $U$ - tests (a non parametric equivalent to t-test) were conducted. There was a nonnormal distribution across each variable and in each group as the Kolmogorov-Smirnov tests were significant for each questionnaire $(p<.01)$, thus the assumption of normality for analysis of variance (ANOVA) was violated. Spearman rho correlations between attachment avoidance, attachment anxiety and body dissatisfaction, drive for thinness and bulimia were conducted to examine the relationship between these variables.

\section{Results}

The results of descriptive statistics revealed that $17.9 \%$ of subjects were underweight, $77.8 \%$ had a normal weight and $4.6 \%$ were overweight. The strongest correlation was found between body mass and drive for thinness $\left(r_{\text {ho }}=.429, p<01\right)$, whereas the relationships between body mass, body dissatisfaction and bulimia were weaker $\left(r_{h o}=.287, p<.01, r_{h o}=.185\right.$, $p<.01$ ), indicating that individuals with higher body mass index tend to engage in more weight controlling practices than those underweight or with normal weight (tab. 3.1).

Table 3.1. Correlations among all variables as calculated by Spearman's rho.

\begin{tabular}{|c|c|c|c|c|}
\hline Variable & 1 & 2 & 3 & 4 \\
\hline Body dissatisfaction & 1 & & & \\
\hline Drive for thinnes & $458^{* *}$ & 1 & & \\
\hline Bulimia & $.285 * *$ & $.293^{* *}$ & 1 & \\
\hline Body Mass & $.287 * *$ & $.429 * *$ & $.157^{* *}$ & 1 \\
\hline
\end{tabular}

To test if there were significant differences between groups of participants in dimensions of maternal attachment avoidance and attachment anxiety with respect to body dissatisfaction, drive for thinness and bulimia a series of separate Mann - Whitney $U$ tests were conducted. Mann - Whitney $U$ tests indicated that there were significant differences between groups of participants in attachment avoidance with their mother in respect to body dissatisfaction $(U=57140, z$ 
$=5.965, p=.001)$ and bulimia $(U=66575, z=2.966, p=.003)$, whereas no significant difference was found among groups in attachment avoidance in regard to drive for thinness $(U=70841, z=1.599, p=.110)$.(tab.3.2).

Table 3.2. Results of Mann-Whitney U-tests comparing low attachment avoidance $(n=388)$ and high attachment avoidance $(n=391)$.

\begin{tabular}{|c|c|c|c|c|}
\hline & $\begin{array}{c}\text { Attachment } \\
\text { avoidance } \\
\text { (low) } \\
\text { Md }\end{array}$ & $\begin{array}{l}\text { Attachment } \\
\text { avoidance } \\
\text { (high) } \\
\text { Md }\end{array}$ & $\mathrm{z}(\mathrm{C})$ & Sig. \\
\hline Body dissatisfaction & 19 & 23 & $\begin{array}{c}-5.965 \\
(57140.500)\end{array}$ & $<.001$ \\
\hline Drive for thinness & 6.5 & 8 & $\begin{array}{c}-1.599 \\
(70841.500)\end{array}$ & .110 \\
\hline Bulimia & 4 & 5 & $\begin{array}{r}-2.966 \\
(66575.00)\end{array}$ & $<.003$ \\
\hline
\end{tabular}

Differences were also found among anxiety attachment groups in respect to body dissatisfaction $(U=41334, z=3.475, p$ $=.001)$, drive for thinness $(U=42780, z=2.910, p=.004)$ and bulimia $(U=32699, z=6.878, p=.001)$.(tab.3.3).

Table 3.3. Results of Mann-Whitney U-tests comparing low attachment anxiety group $(n=616)$ and high attachment anxiety group $(n=163)$.

\begin{tabular}{lccccc}
\hline & $\begin{array}{c}\text { Attachment } \\
\text { anxiety } \\
\text { (low) } \\
\text { Md }\end{array}$ & $\begin{array}{l}\text { Attachment } \\
\text { anxiety } \\
\text { (high) } \\
\text { Md }\end{array}$ & $\mathrm{Z}(\mathrm{C})$ & Sig. \\
\hline Body dissatisfaction & 20 & 23 & $\begin{array}{c}3.475 \\
(41334.000)\end{array}$ & $<.001$ \\
Drive for thinness & 6 & 9 & $\begin{array}{c}-2.910 \\
(42780.500)\end{array}$ & $<.004$ \\
Bulimia & 4 & 7 & -6.878 & $<.001$ \\
& & & $(32699.00)$ & \\
\hline
\end{tabular}

The associations between attachment avoidance and attachment anxiety dimensions among Albanian female students and body dissatisfaction, drive for thinness and bulimia were tested using Spearman rho correlations. Results indicated that the strongest correlation was found between attachment avoidance and body dissatisfaction ( $r_{h o}=.258, p<.01$ ), whereas a weaker correlation, although statistically significant, was found between attachment avoidance with mother, bulimia ( $\mathrm{h}_{\mathrm{ho}}=.143, \mathrm{p}<.01$ ) and drive for thinness ( $\left.\mathrm{h}_{\mathrm{h}}=.078, \mathrm{p}<.01\right)$. Regarding attachment anxiety, it was revealed that this dimension had a stronger association with bulimia $\left(\mathrm{r}_{\mathrm{ho}}=.275, \mathrm{p}<.01\right)$ when compared with body dissatisfaction ( $\mathrm{r}_{\mathrm{ho}}=$ $.109, p<.01)$ and drive for thinness ( $\left.r_{n o}=.108, p<.01\right) .(t a b .3 .4)$.

Table 3.4. Correlations between avoidance and anxiety attachment ratings and EDI scores

\begin{tabular}{lcl}
\hline & $\begin{array}{c}\text { Attachment } \\
\text { avoidance }\end{array}$ & $\begin{array}{c}\text { Attachment } \\
\text { anxiety }\end{array}$ \\
\hline $\begin{array}{l}\text { Body Dissatisfaction } \\
\text { Dive for Thinness } \\
\text { Bulimia }\end{array}$ & $.258^{* *}$ & $.109^{* *}$ \\
& $.078^{* *}$ & $.108^{* *}$ \\
Note: ${ }^{* *} p<.01$ & $.143^{* *}$ & $.275^{* *}$ \\
\hline
\end{tabular}

\section{Discussion}

The purpose of the present study was to investigate the relationship of maternal attachment avoidance and attachment anxiety with body dissatisfaction, drive for thinness and bulimia among Albanian female college students. The variable 
tested was BMI for demographic characteristics, while attachment avoidance and attachment anxiety with mother were tested for psychological constructs. As expected, results showed that girls with higher BMI tend to engage more in weight controlling practices in comparison with underweight and normal weight counterparts, while showing also higher levels of body dissatisfaction and bulimia. These findings are consistent with many studies indicating that overweight and obese girls display elevated risk for weight and shape concerns and dieting attempts, which in turn are associated with more dysfunctional eating habits. Body dissatisfaction and weight control practices are potent predictors for future oneset of full and sub-threshold anorexia nervosa and bulimia nervosa (Camarg01999, Gowers \& Shore, 2001; Vogeltanz-Home et al.,2000; Killen et al., 1996).

Also it was hypothesized that higher levels of attachment avoidance and attachment anxiety of girls with their mother will predict higher disordered eating as measured through body dissatisfaction, drive for thinness and bulimia. Differences between groups of avoidant attachment and anxious attachment in regard to eating disorder attitudes and behaviors were revelead. Mann-Whitney $U$ tests confirmed the expectation that highly avoidant and anxious girls would score higher in levels of body dissatisfaction, drive for thinnes and bulimia when compared to girls scoring low in attachment avoidance and anxiety with their mothers.

Correlation analysis between avoidance and anxiety attachment dimensions revealed a positive and a statistically significant correlation with body dissatisfaction, drive for thinness and bulimia. Attachment avoidance had a stronger correlation with body dissatisfaction when compared to the association with drive for thinness and bulimia. This is consistent with theories linking avoidant attachment to eating disorder symptomatology (Brennan \& Shaver,1995; ColeDetke \& Kobak, 1996; Latzer et al., 2002). Also attachment anxiety was found to be more strongly associated with bulimia when compared to body dissatisfaction and drive for thinness. Differences between attachment anxiety and attachment avoidance with mother in respect to eating disorder symptomatology may be due to different attachment strategies that are activated by young girls when faced with distress. The stronger relationship between attachment anxiety and bulimia may be explained with hyperactivation as an emotional management strategy that individuals with anxious attachment typically use as a way of coping with difficult emotions. Also, the link between the emotional management strategy of deactivation in individuals with avoidant attachment style and higher levels of eating disorder symptoms were supported in a study by Cole-Detke \& Kobak (1996).

Although the present study cannot determine a casual relationship between insecure attachment with mother and eating disorder attitudes and behaviours, attachment style is a personality factor that develops early in life and remains relatively stable across the life span (Rothbart\& Shaver,1994; Waters et al., 2000). As a consequence, attachment insecurity with mother may have an impact on developing certain disordered eating habits and attitudes in late adolescent females that display high levels of attachment avoidance and anxiety.

Despite the contribution in enhancing the existing knowledge about eating disorders during late adolescence and young adulthood in Albanian females there are some limitations of the present study. The homogenous sample limits the generalizability of results for other groups. Results of the present study indicated that attachment insecurity with mother as measured through avoidance and anxiety dimensions was modestly related to body dissatisfaction, drive for thinness and bulimia. Further studies are needed to confirm if insecure attachment with mother plays a role in triggering the development of eating disorders among late adolescent girls.

\section{Recommendations}

Prevention and treatment programs should be enhanced by focusing attention on attachment relationships as global intervention programs are viewed as less effective than selective ones (Irvin \& Neumark-Sztainer, 2002; Stice \& Shaw, 2004). Specific intervention programs focused on strengthening the sense of security in attachment relationships could reduce the vulnerability especially of adolescent and young adulthood females toward development of eating disorder symptoms. Also, specific educational programmes focused on the importance of early establishing healthy eating attitudes and behaviors should be implemented in Albanian schools. Further studies in this area should be carried to address the complex interplay of various factors contributing to eating disorder pathologies.

\section{References}

Ainsworth, M.D., Blehar, M, Waters, E, \& Wall, S (1978). Patterns of Attachment: A Psychological Study of the Strange Situation, Hillsdale, NJ: Lawrence Erlbaum

Armstrong, J. G., \& Roth, D. M (1989). Attachment and separation difficulties in eating disorders: A preliminary investigation. International Journal of Eating Disorders, 8, 141-155. 
Brennan, K. A., Clark, C. L., \& Shaver, P.R (1998). Self-report measurement of adult attachment: An integrative overview. In J. A. Simpson and W. S. Rholes (Eds.), Attachment theory and close relationships (pp. 46-76). New York: Guilford Press.

Brennan, K. A., \& Shaver, P. R (1995). Dimensions of adult attachment, affect regulation, and relationship functioning. Personality and Social Psychology Bulletin, 21, 267-283.

Clay, D., Vignoles, L.V., \& Ditmar, H (2005). Body image and self-esteem among adolescent girls: Testing the influence of socicultural factors. Journal of Research on Adolescence, 15 (4),451-477.

Cole-Detke, H., Kobak, R (1996). Attachment processes in eating disorder and depression. Journal of Consulting and Clinical Psychology, 64 (2): 282-90.

Collins, N., \& Read, S (1990). Adult attachment, working models, and relationship quality in dating couples. Journal of Personality and Social Psychology, 58, 644-663.

Fairburn, C.G, Shafran, R., \& Coooper, Z (1998). A cognitive behavioral theory of anorexia nervosa. Behaviour Research and Therapy, $37(1): 1-13$.

Field, A., Camargo, C.J., Taylor, C., Berkey, C., Colditz, G (1999): Relation of peer and media influences to the development of purging behaviours among preadolescent and adolescent girls. Archive Pediatric Adolescence Medicine, 153(11): 1184-1189.

Fraley, R.C., Waller, N.G., Brennan, K.A (2000): An item response theory analysis of self-report measures of adult attachment. Journal of Personality and Social Psychology, 78 (2):350-365.

Fraley, R.C (2002). Attachment stability from infancy to adulthood: Meta-analysis and dynamic modeling of developmental mechanisms. Personality and Social Psychology Review, 6,123-151.

Furnham, A., Badmin, N., and Sneade, I (2002) "Body image dissatisfaction: Gender differences in eating attitudes, self esteem, and reasons for exercise." Journal of psychology,136 (6), 581- 596.

Gamble, S.A., Roberts, J.E. (2005). Adolescents' perceptions of primary caregivers and cognitive style: The roles of attachment security and gender. Cognitive Therapy and Research, 29: 123-141.

Garner, M.D (2004). The Eating Disorder Inventory-3: Professional manual. Odessa, FL: Psychological Assessement Resources, Inc.

Griffin, D., \& Bartholomew, K (1994b). Models of the self and other: Fundamental dimensions underlying measures of adult attachment. Journal of Personality and Social Psychology, 67, 430-445.

Govers, S., Shore, A (2001). Development of weight and shape concerns in the aetiology of eating disorders. British Journal of Psychiatry, 179: 236-242.

Hazan, C., Shaver, P.R. (1987). Romantic love conceptualized as an attachment process. Journal of Personality and Social Psychology, 52: 511-524.

Irving, L.M, Neumark-Sztainer, D (2002). Integrating the prevention of eating disorders and obesity: feasible or futile? Preventive Medicine, 34:299-309. 31.

Latzer, Y. et al. (2002). Attachment style and family functioning as discriminating factors in eating disorders. Contemporary Family Therapy: An International Journal, 24 (4), 581-600.

Killen J, Taylor C, Hayward K, Wilson D, Hammer L, Kraemer H, Blair-Greiner A, Strachowski, D (1999). Weight concerns influence the development of eating disorders: a 4-year prospective study. Journal of Consulting and Clincal Psychology, 64 (5): $936-940$.

Magai, C., Distel, N., \& Liker, R (1995). Emotion socialisation, attachment, and patterns of adult emotional traits. Cognition and Emotion, 9, 461-481.

Ramacciotti, A., Sorbello, M., Pazzagli A., Vismara, L., Mancone, A., Pallanti, S. (2001). Attachment processes in eating disorders. Journal of Eating Disorders. 6: 166-170.

Roberts, J., Gotlib, H.I., Kassel, J.D (1996): Adult attachment and symptoms of depression: The mediating role of dysfunctional attitudes an low self-esteem. Journal of Personality and Social Psychology, 70 (2) 310-320.

Rothbard, J.C., Shaver, P. R (1994). Continuity of attachment across the life span. In: Sperling MB, Berman WH, eds. Attachment in Adults: Clinical and Developmental Perspectives. New York: Guilford; 31-71.

Polivy, J. Herman, P.C (2002). Causes of eating disorders. Annual Review of Psychology. 53: 187-213.

Stice, E., Shaw, H (1994). Adverse effects of the media portrayed thin-ideal on women and linkages to bulimic symptomatology. Journal of Social and Clinical Psychology. 13 (3):288-308.

Stice, E., Shaw, H (2004). Eating disorder prevention programs: a meta-analytic review. Psychology Bulletin;130:206 -27.

Tasca, G. A., Szadkowski, L., Illing, V., Trinneer, A., Grenon, R., \& Demidenko, N., et al., (2009). Adult attachment, depression, and eating disorder symptoms: The mediating role of affect regulation strategies. Personality and Individual Differences.47: 662- 667.

Troisi, A., Di Lorenzo, G., Alcini, S., Nanni, R.C., Di Pasquale, C., Siracusano (2006). Body dissatisfaction in women with eating disorders: relationship to early separation anxiety and insecure attachment. Psychosomatic Medicine, 68 (3): 449-53.

Vogeltanz-Holm, N.D., Wonderlich, S.A., Lewis, B.A., Wilsnack, S.C., Harris, T.R., Wilsnack, R.W., Kristjanson, A.F (2000): Longitudinal predictors of binge eating, intense dieting and weight concerns in a national sample of women. Behavioural Therapy, 31 (2): 221 235.

Warren, S., Huston, L., Egeland, B., \& Sroufe, L.A (1997). Child and adolescent anxiety disorders and early attachment. Journal for the American Academy of Child and Adolescent Psychiatry, 36, 637- 644.

Waters, E., Merrik. S., Treboux, D., Crowell, J., Albersheim, L (2000). Attachment security in infancy and early adulthood: a twenty-year longitudinal study. Child Development, 71: 684 -9. 